\title{
Análise centesimal dos cortes da carcaça de cordeiros Santa Inês e Bergamácia
}

\author{
Chemical composition of carcass cuts of Santa Ines and Bergamacia lambs
}

Cristiane Leal dos SANTOS ${ }^{1 *}$, Juan Ramón Olalquiaga PEREZ ${ }^{2}$, Christian Albert Carvalho da CRUZ
Joel Augusto MUNIZ

\section{Resumo}

O trabalho foi conduzido no Setor de Ovinocultura do Departamento de Zootecnia da UFLA, em Lavras, com objetivo de determinar a composição química dos cortes da carcaça (perna, lombo, costeleta e costela/fralda), em relação ao peso do corpo vazio de cordeiros Santa Inês e Bergamácia. Foram utilizados 36 cordeiros machos inteiros, sendo 24 Santa Inês e 12 Bergamácia, abatidos ao atingirem 15, 25, 35 e $45 \mathrm{~kg}$ de peso vivo. Os cordeiros foram confinados em gaiolas individuais onde receberam alimentação ad libitum até o abate. Realizou-se a retirada da pele e evisceração pesando-se o trato digestivo, bexiga e vesícula biliar, cheios e vazios, para determinação do peso corporal vazio (PCVZ). A carcaça foi resfriada a $2{ }^{\circ} \mathrm{C}$ por um período de 24 horas e depois de retirado o pescoço, foi seccionada em metades simétricas. $\mathrm{Na} 1 / 2$ carcaça procedeu-se a divisão em cortes, dos quais foram utilizados e analisados: perna, lombo, costeleta e costela/fralda. O melhor momento de abate dos cordeiros Santa Inês e Bergamácia seria na faixa de 25 e $35 \mathrm{~kg}$ de peso vivo, quando os cortes apresentariam as melhores proporções de água, proteína, gordura e minerais, refletindo melhores aspectos de qualidade.

Palavras-chave: costela/fralda; costeleta; gordura; lombo; perna; proteína.

\begin{abstract}
The work was conducted at the Sheep Production Sector of the Animal Science Department of the UFLA in Lavras with a view to determining the chemical composition of Santa Ines and Bergamacia lambs carcass cuts (leg, loin, ribs and breast), relative to the empty body weight. Thirty-six non-castrated, male lambs were used, 24 of them being Santa Ines and 12 Bergamacia, slaughtered when they reached 15, 25, 35 and $45 \mathrm{~kg}$ of live weight. The lambs were confined in individual cages, where they were fed ad libitum until the moment of slaughter. Removal of the skin and evisceration were performed, weighing the digestive tract, bladder and gall bladder, full and empty, to determine empty body weight. The carcass was cooled $\left(2^{\circ} \mathrm{C}\right)$ for a 24 -hour period and, after the neck was removed, it was sectioned into symmetric halves. In half of the carcass, division in cuts was preceded, from which leg, loin, ribs and breast were utilized for the analysis of the chemical composition. The best moment to slaughter the Santa Ines and Bergamacia lambs would be in the range of 25 and $35 \mathrm{~kg}$ of live weight, where cuts would present the best ratios of water, protein, fat and minerals, reflecting better quality.

Keywords: rib/flank; rack; fat; loin; leg; protein.
\end{abstract}

\section{Introdução}

Os principais componentes químicos do corpo são: água, proteína, gordura e cinzas. Com o avançar da idade, ocorre um incremento na proporção de gordura, acompanhado por uma diminuição de água e proteína no corpo. Animais jovens apresentam normalmente o corpo rico em água e proteína, o que implica que a relação água: proteína continua diminuindo lentamente com a idade.

O peso corporal exerce uma grande influência na composição da carcaça dos animais em crescimento, independente da velocidade de crescimento. De acordo com Berg e Butterfield (1976), há um paralelismo entre os modelos de crescimento dos componentes químicos, como: água, proteína, gordura e cinzas; e dos fisicamente separados, como: músculo, gordura e ossos, onde aproximadamente $50 \%$ da água e proteína corporais estão no músculo, e a gordura nos depósitos de gordura, além do que o crescimento muscular se revela pelo aumento da água e proteína do corpo. Os tecidos musculares contêm certas quantidades de gordura assim como proteína, água e cinzas, e o tecido adiposo não está composto exclusivamente por gordura, sendo que ocorre a presença também de proteína e água.

Grande parte das informações sobre a composição química do corpo, que se encontra na literatura científica, tem sido obtida a partir de análises químicas do corpo inteiro do animal. A composição química do corpo inteiro do animal tem sido utilizada como critério fundamental para determinar a resposta, por parte dos animais, a tratamentos nutritivos, além de ser possível conhecer quantitativamente a forma em que o animal utiliza os elementos nutritivos químicos para construir seu corpo.

Em Nutrição e Produção Animal é crucial, ao estudar ou avaliar o crescimento, que sejam definidas unidades bioquímicas

Recebido para publicação em 5/7/2006

Aceito para publicaçào em 18/12/2007 (001788)

Projeto financiado pela Fapemig

Departamento de Tecnologia Rural e Animal - DTRA, Universidade Estadual do Sudoeste da Bahia - UESB, Campus Juvino Oliveira, Br 145, Km 3, Itapetinga - BA, Brasil E-mail: crisleal@uesb.br

2 Departamento de Zootecnia, Universidade Federal de Lavras - UFLA, CP 37, CEP 37200-000, Lavras - MG, Brasil

${ }^{3}$ Departamento de Ciências Exatas, Universidade Federal de Lavras - UFLA, CP 37, CEP 37200-000, Lavras - MG, Brasil

${ }^{*}$ A quem a correspondência deve ser enviada 
depositadas, pois segundo Lanna et al. (1992) é preciso conhecer as vias metabólicas utilizadas para a deposição desses constituintes corporais, para que seja possível definir uma série de parâmetros que podem influenciar no desempenho animal.

Santos (1999) verificou que os cordeiros Santa Inês, quando se aproximam dos $45 \mathrm{~kg}$ de peso vivo, têm em relação ao desenvolvimento muscular um ritmo mais lento, aumentando o ritmo de gordura, o que vem a ser um aspecto indesejável, porém, analisando outras raças consideradas aptas à produção de carne e que apresentam comportamento semelhante à Santa Inês, isto deixa de ser específico a esta raça.

Santos e Pérez (2000) verificaram que o peso de abate mais adequado dos cordeiros Santa Inês deve se situar entre 25 e $35 \mathrm{~kg}$ de peso vivo. Nesta faixa de peso é quando de forma geral todos os cortes, e em particular, os cortes de primeira como a perna, a costeleta e o lombo, obtidos no sistema proposto, apresentam as melhores proporções analisadas, refletindo melhores aspectos de qualidade para o consumidor final, e em função disso uma melhor valorização do produto oferecido por parte do produtor.

Portanto, a determinação da quantidade de tecidos ou órgãos depositados é de grande importância, definindo os componentes que possuem os mesmos valores calóricos e semelhantes vias metabólicas de deposição. Sob este ponto de vista, acredita-se que gordura, proteína, água e cinzas são os componentes corporais a serem determinados.

A não existência de resultados nas condições brasileiras, principalmente para as raças Santa Inês e Bergamácia, levou à realização deste estudo, objetivando determinar a composição química dos cortes da carcaça, costeleta, costela/fralda, lombo e perna de cordeiros abatidos com diferentes pesos.

\section{Material e métodos}

Após a evisceração e a retirada da cabeça, pés, cauda e testículos, obteve-se a carcaça inteira do animal, a qual foi pesada para obtenção do peso da carcaça quente (PCQ), a qual foi levada à câmara fria com temperatura de $2{ }^{\circ} \mathrm{C}$ por um período de 24 horas, e para que não ocorresse encurtamento das fibras, as carcaças foram mantidas penduradas pela articulação tarso metatarsiana em ganchos próprios, com distanciamento de $17 \mathrm{~cm}$. Após esse período, a carcaça foi pesada para a tomada do peso da carcaça fria (PCF). A partir de então, procedeu-se à retirada do pescoço através de um corte oblíquo que passou entre a sexta e a sétima vértebra cervical, buscando a ponta do esterno e terminando na borda inferior do pescoço. Em seguida, mediante corte longitudinal na carcaça, obtiveram-se metades aproximadamente simétricas, pesando-se a $1 \frac{1}{2}$ carcaça esquerda. Para isto, em primeiro lugar, seccionou-se a sínfise ísquio-pubiana, seguindo o corpo e a apófise espinhosa do sacro, das vértebras lombares e dorsais.

Os cortes, costeleta, costela/fralda, lombo e perna, foram pesados e acondicionados em sacos plásticos e mantidos no freezer, a uma temperatura de $-10^{\circ} \mathrm{C}$, até o momento de serem processados para análise química.
A composição química dos cortes comerciais permitiu a determinação do comportamento dos componentes químicos corporais (água, gordura, proteína e cinzas) presentes nos cortes comerciais em função do peso do animal.

Os cortes comerciais foram armazenados em freezer a uma temperatura de aproximadamente $10^{\circ} \mathrm{C}$, aguardando o momento de serem moídos alternadamente. Ainda congelados, os cortes foram reduzidos em cubos fazendo-se uso de uma serra elétrica. Imediatamente os cubos eram inseridos no moinho de carne elétrico e assim realizada a primeira moagem. Mais duas moagens foram realizadas para homogeneizar a amostra, a qual foi colocada numa bacia própria e então foram feitos, manualmente, movimentos circulares para uma melhor mistura dos componentes teciduais. Na parte central da amostra retirou-se uma subamostra (150 a 200 g), que foi utilizada para as análises químicas. O corte foi amostrado e em seguida colocado em placas de petri envolvidas por papel filme e congeladas à temperatura de $5{ }^{\circ} \mathrm{C}$ para posterior liofilização.

Foi utilizado o processo de liofilização da amostra para obtenção da umidade e matéria seca. A subamostra foi colocada numa placa de petri previamente pesada e envolvida em papel filme. Após obter o peso úmido, a sub-amostra foi acondicionada em freezer a uma temperatura de $5^{\circ} \mathrm{C}$ e só retirada no momento de ser colocada no liofilizador, onde permaneceu por 48 horas à temperatura de $-40^{\circ} \mathrm{C}$, a vácuo. Passado este período, as placas eram retiradas do equipamento, levadas a um dessecador e em seguida pesadas para obtenção do peso seco.

Após a retirada da umidade, a subamostra liofilizada foi desengordurada parcialmente para facilitar uma nova moagem, visando uma melhor uniformização da amostra e redução mínima do tamanho da partícula, obtendo assim amostras mais representativas.

Para isso, toda subamostra liofilizada foi colocada em um pacote feito de papel filtro Germitest Tipo Cel 065, e em seguida fechado com grampos e levado à estufa a $65^{\circ} \mathrm{C}$, permanecendo por 16 a 24 horas para obtenção do peso seco. Os pacotes foram posteriormente mergulhados em éter etílico num dessecador, onde permaneciam por um período de aproximadamente 24 horas. Durante este período, normalmente era feita a troca do éter para que houvesse uma melhor retirada de gordura parcial. Após este período os pacotes eram retirados do dessecador, colocados numa bandeja para exalar o éter etílico, e levados novamente à estufa a $65^{\circ} \mathrm{C}$ até peso constante, o que correspondia a um período de 16 a 24 horas. Com isso obtinha-se o peso seco desengordurado.

O cálculo da percentagem de gordura parcial foi feito considerando a fórmula 1.

$$
\left.\begin{array}{c}
\text { Gordura } \\
\text { parcial }
\end{array}=\frac{\left(\begin{array}{cc}
\text { Peso seco do pacote com } \\
\text { amostra liofilizada }(\mathrm{g})
\end{array}\right.}{\begin{array}{l}
\text { Peso seco do pacote } \\
\text { com amostra liofilizada } \\
\text { desengordurada }(\mathrm{g})
\end{array}}\right)
$$

Peso da amostra liofilizada $=[($ Peso seco do papel + grampo + amostra $)$ - (Peso seco do papel + grampo $)]$ 
As amostras liofilizadas e desengorduradas parcialmente foram retiradas dos pacotes e novamente moídas em moinho do tipo martelo para melhor uniformização. Esta amostra serviu para determinação do extrato etéreo residual, proteína bruta, cinzas e energia bruta.

A determinação da gordura residual presente na subamostra foi realizada através da extração com o aparelho Soxhlet. Foram utilizadas umas quantidades de amostra que variou de 0,5 a $1,0 \mathrm{~g}$. Foram preparados pacotes de papel filtro qualitativo para colocar a amostra que seria analisada. Para cada corte foram feitas 3 repetições. Para extração, estes pacotes foram colocados em recipientes com éter etílico durante o tempo necessário, o qual correspondia ao momento em que o éter contido no balão não sofresse mais alterações de cor devido à presença de gordura. Após este período, que variou de 20 a 30 horas, os pacotes foram colocados numa estufa a $105^{\circ} \mathrm{C}$ por 12 horas, e com isso obtido o peso seco após extração. A quantidade total de extrato etéreo foi calculada como a perda de matéria seca durante a extração, levando em consideração também a quantidade de gordura que saiu da subamostra durante o desengorduramento parcial, de acordo as fórmulas 2 e 3 :

$$
\% \text { Gordura total }=\frac{(\text { Gordura parcial }+ \text { Gordura residual })}{\text { Peso da amostra liofilizada }(\mathrm{g})}
$$

Gordura residual (extrato etéreo) $=$ cálculo semelhante ao realizado para obter a gordura parcial, sendo modificada a quantidade de amostra utilizada (0,5 g a $1,0 \mathrm{~g})$

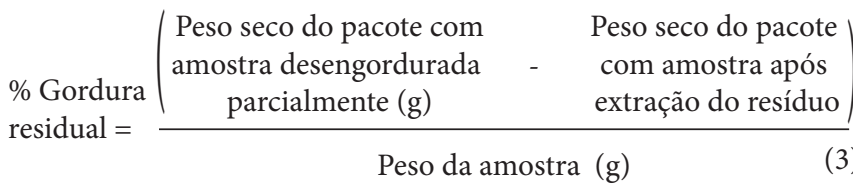

A determinação da proteína bruta foi feita através do método de micro Kjedhal com 200 mg de amostra desengordurada, utilizando-se $10 \mathrm{~mL}$ de ácido sulfúrico para digestão da amostra fazendo-se de 2 a 3 réplicas, segundo método da A.O.A.C(1990). O número de repetições dependeu da quantidade de amostra disponível para todas as análises químicas. Isso ocorreu porque animais mais novos (15 kg de peso vivo) não permitiram obtenção de uma quantidade considerada de subamostra.

O teor de cinzas e/ou matéria mineral foi obtido a partir da queima a $600{ }^{\circ} \mathrm{C}$ por 16 horas, do material desengordurado obtido pelo procedimento descrito acima.

Utilizou-se $1 \mathrm{~g}$ de amostra desengordurada e duas repetições para cada corte. Os valores foram determinados através da bomba calorimétrica.

Considerando a ocorrência de erro laboratorial e de preparo da amostra, foi realizado um intervalo de confiança para os valores obtidos nas análises de umidade, extrato etéreo, proteína e cinzas. Com este estudo, verificou-se a necessidade ou não de repetir alguma análise química e ainda definir a percentagem de erro admitido. O intervalo de confiança foi feito através do PROC SUMARY do SAS (1996).
As amostras deveriam ser reanalisadas sempre que a soma da percentagem de proteína, a percentagem de gordura, mais a de cinzas e a de água fosse menor que 95,0 ou maior que 105,00 .

O delineamento experimental utilizado foi inteiramente casualizado (DIC), num esquema fatorial $4 \times 2$, sendo 4 pesos de abate, 15, 25, 35 e $45 \mathrm{~kg}$ e 2 raças, sendo 6 repetições para a raça Santa Inês e 3 para a Bergamácia, onde cada animal representou uma repetição. Para obtenção dos resultados utilizou-se o PROC GLM do SAS (1996).

Para explicar melhor a variação que $\mathrm{X}$ exerceu sobre $\mathrm{Y}$ ou a verdadeira dependência que $Y$ tem em relação a $X$, utilizou-se o Programa TABLE CURVE para selecionar uma equação de regressão que melhor ajustasse os valores observados, apresentando estimativas que minimizassem o desvio. Realizou-se ainda, a probabilidade do teste $\mathrm{F}$ para o coeficiente de regressão através do programa FCALC.

\section{Resultados e discussão}

Os componentes químicos mais importantes de qualquer organismo animal são: proteína, gordura ou extrato etéreo e água ou umidade (POVEDA, 1984), incluindo os minerais. Hammond (1932), Palsson (1990) e Hankins (1947), Gee e Preston (1957) e Kirton e Barton (1958) citados por Poveda (1984) indicaram que uma maior precisão na composição das carcaças ovinas é conseguida mediante a separação física das mesmas e posterior análise química das diferentes partes.

Nas Tabelas 1, 2, 3 e 4 é apresentada a composição química em g. $100 \mathrm{~g}^{-1}$ de extrato etéreo (EE), proteína bruta (PB), cinzas (CIN) e umidade (UM) da costeleta, costela/fralda, lombo e perna, respectivamente.

Tabela 1. Valores médios e respectivos erros padrão do extrato etéreo (EE), proteína bruta $(\mathrm{PB})$, cinza $(\mathrm{CIN})$ e umidade (UM) na matéria natural da costeleta de cordeiros Santa Inês e Bergamácia abatidos com diferentes pesos.

\begin{tabular}{|c|c|c|c|c|}
\hline $\begin{array}{l}\text { Peso de } \\
\text { abate }\end{array}$ & $\mathrm{EE}$ & $\mathrm{PB}$ & CIN & UM \\
\hline $\mathrm{Kg}$ & \multicolumn{4}{|c|}{ g. $100 \mathrm{~g}^{-1}$} \\
\hline \multicolumn{5}{|l|}{ Santa Inês } \\
\hline 15 & $12,92^{(0,39)^{*}}$ & $18,83^{(0,68)}$ & $6,24^{(0,44)}$ & $61,99^{(0,92)}$ \\
\hline 25 & $15,55^{(0,30)}$ & $23,24^{(0,58)}$ & $5,19^{(0,51)}$ & $55,24^{(0,58)}$ \\
\hline 35 & $17,76^{(0,19)}$ & $21,90^{(0,22)}$ & $3,88^{(0,63)}$ & $54,94^{(0,60)}$ \\
\hline 45 & $23,29^{(0,70)}$ & $20,49^{(0,55)}$ & $3,69^{(0,37)}$ & $52,52^{(0,41)}$ \\
\hline \multicolumn{5}{|l|}{ Bergamácia } \\
\hline 15 & $10,95^{(0,82)}$ & $17,71^{(0,71)}$ & $5,71^{(0,17)}$ & $65,62^{(1,34)}$ \\
\hline 25 & $16,69^{(0,82)}$ & $22,77^{(1,24)}$ & $5,43^{(0,88)}$ & $54,10^{(1,07)}$ \\
\hline 35 & $17,77^{(0,91)}$ & $20,37^{(0,53)}$ & $3,48^{(0,29)}$ & $57,37^{(0,30)}$ \\
\hline 45 & $25,73^{(0,45)}$ & $20,06^{(0,62)}$ & $3,30^{(0,47)}$ & $51,23^{(0,79)}$ \\
\hline \multicolumn{5}{|l|}{ Raça } \\
\hline SI & $17,38^{(0,82)}$ & $21,11^{(0,42)}$ & $4,75^{(0,31)}$ & $56,20^{(0,78)}$ \\
\hline BG & $17,78^{(1,62)}$ & $20,23^{(0,64)}$ & $4,48^{(0,40)}$ & $57,08^{(1,67)}$ \\
\hline Prob > F' & 0,1712 & 0,7368 & 0,7143 & 0,0971 \\
\hline Prob $>\mathrm{T}$ & 0,8268 & 0,2648 & 0,5981 & 0,6411 \\
\hline
\end{tabular}

*Erro padrão da média. 
Tabela 2. Valores médios e respectivos erros padrão do extrato etéreo (EE), proteína bruta $(\mathrm{PB})$, cinza (CIN) e umidade (UM) na matéria natural da costela/fralda de cordeiros Santa Inês e Bergamácia abatidos com diferentes pesos.

\begin{tabular}{|c|c|c|c|c|}
\hline Peso de abate & $\mathrm{EE}$ & $\mathrm{PB}$ & CIN & UM \\
\hline $\mathrm{kg}$ & \multicolumn{4}{|c|}{ g. $100 \mathrm{~g}^{-1}$} \\
\hline \multicolumn{5}{|l|}{ Santa Inês } \\
\hline 15 & $16,26^{(0,43)^{*}}$ & $18,86^{(0,53)}$ & $5,67^{(0,85)}$ & $59,20^{(1,45)}$ \\
\hline 25 & $25,66^{(0,76)}$ & $20,17^{(0,57)}$ & $2,98^{(0,50)}$ & $51,01^{(0,86)}$ \\
\hline 35 & $29,65^{(0,87)}$ & $17,57^{(0,21)}$ & $3,29^{(0,49)}$ & $49,30^{(0,52)}$ \\
\hline 45 & $32,98^{(0,39)}$ & $15,11^{(0,41)}$ & $3,38^{(0,68)}$ & $48,52^{(0,96)}$ \\
\hline \multicolumn{5}{|l|}{ Bergamácia } \\
\hline 15 & $17,21^{(0,35)}$ & $15,57^{(0,76)}$ & $5,04^{(0,77)}$ & $61,83^{(0,45)}$ \\
\hline 25 & $26,67^{(0,52)}$ & $19,26^{(0,46)}$ & $3,87^{(0,48)}$ & $50,18^{(0,05)}$ \\
\hline 35 & $37,86^{(0,67)}$ & $16,11^{(0,72)}$ & $4,07^{(0,64)}$ & $41,95^{(0,43)}$ \\
\hline 45 & $39,23^{(0,43)}$ & $15,84^{(1,06)}$ & $4,42^{(0,69)}$ & $40,51^{(0,69)}$ \\
\hline \multicolumn{5}{|l|}{ Raça } \\
\hline SI & $26,13^{(1,34)}$ & $17,93^{(0,44)}$ & $3,83^{(0,37)}$ & $52,01^{(1,00)}$ \\
\hline BG & $30,24^{(2,70)}$ & $16,69^{(0,56)}$ & $4,35^{(0,31)}$ & $48,62^{(2,56)}$ \\
\hline Prob $>F^{\prime}$ & 0,1439 & 0,7148 & 0,0672 & 0,0162 \\
\hline Prob $>\mathrm{T}$ & 0,1929 & 0,0964 & 0,2946 & 0,2378 \\
\hline
\end{tabular}

${ }^{\star}$ Erro padrão da média.

Tabela 3. Valores médios e respectivos erros padrão do extrato etéreo (EE), proteína bruta $(\mathrm{PB})$, cinza $(\mathrm{CIN})$ e umidade (UM) na matéria natural do lombo de cordeiros Santa Inês e Bergamácia abatidos com diferentes pesos.

\begin{tabular}{ccccc}
\hline $\begin{array}{cccc}\text { Peso de abate } \\
\text { kg }\end{array}$ & EE & PB & CIN & UM \\
\cline { 2 - 5 } Santa Inês & \multicolumn{5}{c}{ g.100 g ${ }^{-1}$} \\
\hline 15 & $13,19^{(0,69)^{*}}$ & $19,63^{(0,73)}$ & $4,46^{(0,79)}$ & $63,03^{(0,67)}$ \\
25 & $18,94^{(0,58)}$ & $19,77^{(0,69)}$ & $5,15^{(0,52)}$ & $56,12^{(0,70)}$ \\
35 & $23,19^{(0,65)}$ & $19,00^{(0,50)}$ & $3,79^{(0,32)}$ & $54,00^{(0,31)}$ \\
45 & $28,01^{(0,62)}$ & $17,93^{(0,40)}$ & $2,84^{(0,27)}$ & $51,03^{(0,50)}$ \\
\hline Bergamácia & \multicolumn{5}{c}{} \\
\hline 15 & $13,76^{(0,75)}$ & $16,55^{(0,50)}$ & $6,14^{(0,10)}$ & $62,87^{(0,35)}$ \\
25 & $19,88^{(0,47)}$ & $18,05^{(1,28)}$ & $7,10^{(1,16)}$ & $54,62^{(1,27)}$ \\
35 & $24,75^{(0,84)}$ & $18,02^{(0,17)}$ & $4,37^{(0,30)}$ & $52,85^{(0,84)}$ \\
45 & $30,85^{(1,42)}$ & $15,39^{(1,10)}$ & $3,19^{(0,58)}$ & $50,56^{(0,87)}$ \\
\hline Raça & \multicolumn{5}{c}{} \\
\hline SI & $20,84^{(1,17)}$ & $19,08^{(0,31)}$ & $4,06^{(0,30)}$ & $56,05^{(0,95)}$ \\
BG & $22,31^{(1,93)}$ & $17,00^{(0,50)}$ & $5,20^{(0,54)}$ & $55,23^{(1,45)}$ \\
\hline Prob > F' & 0,5167 & 0,6094 & 0,3264 & 0,7483 \\
\hline Prob > T & 0,5237 & 0,0024 & 0,0826 & 0,6423 \\
\hline
\end{tabular}

${ }^{*}$ Erro padrão da média.

Através dos valores médios apresentados na Tabela 1, verifica-se que não há diferença entre as raças pelo teste $\mathrm{T}$ e $\mathrm{F}$. $\mathrm{O}$ mesmo resultado foi verificado ao analisar os valores médios dos componentes teciduais da costeleta.

Nas Figuras 1 e 2 são observadas as linhas de regressão e respectivas equações que melhor explicam a variação dos componentes químicos da costeleta dos cordeiros Santa Inês e Bergamácia, respectivamente, em relação aos pesos que os animais foram sacrificados. Ocorre um decréscimo do teor de umidade, e aumento considerável de extrato etéreo, o que indica
Tabela 4. Valores médios e respectivos erros padrão da composição química na matéria natural da perna de cordeiros Santa Inês e Bergamácia abatidos com diferentes pesos.

\begin{tabular}{|c|c|c|c|c|}
\hline Peso de abate & $\mathrm{EE}$ & $\mathrm{PB}$ & CIN & $\mathrm{UM}$ \\
\hline $\mathrm{kg}$ & \multicolumn{4}{|c|}{ g. $100 \mathrm{~g}^{-1}$} \\
\hline \multicolumn{5}{|l|}{ Santa Inês } \\
\hline 15 & $11,85^{(0,52)^{*}}$ & $20,27^{(0,16)}$ & $2,97^{(0,28)}$ & $64,39^{(0,73)}$ \\
\hline 25 & $12,72^{(0,82)}$ & $21,84^{(0,76)}$ & $2,57^{(0,27)}$ & $63,12^{(0,78)}$ \\
\hline 35 & $16,45^{(0,44)}$ & $22,50^{(0,39)}$ & $2,22^{(0,40)}$ & $58,15^{(0,35)}$ \\
\hline 45 & $18,80^{(1,10)}$ & $23,54^{(1,40)}$ & $1,30^{(1,08)}$ & $54,55^{(1,77)}$ \\
\hline \multicolumn{5}{|l|}{ Bergamácia } \\
\hline 15 & $10,44^{(0,71)}$ & $20,41^{(0,43)}$ & $3,27^{(0,56)}$ & $65,55^{(0,72)}$ \\
\hline 25 & $13,28^{(0,44)}$ & $20,00^{(1,24)}$ & $2,63^{(0,62)}$ & $63,40^{(0,84)}$ \\
\hline 35 & $16,49^{(1,03)}$ & $21,07^{(0,24)}$ & $2,26^{(0,40)}$ & $59,50^{(0,43)}$ \\
\hline 45 & $25,50^{(0,48)}$ & $25,62^{(0,45)}$ & $2,37^{(0,03)}$ & $45,50^{(0,91)}$ \\
\hline \multicolumn{5}{|l|}{ Raça } \\
\hline SI & $14,80^{(0,71)}$ & $22,04^{(0,45)}$ & $2,50^{(0,19)}$ & $60,05^{(0,95)}$ \\
\hline BG & $16,43^{(1,73)}$ & $21,77^{(0,73)}$ & $2,63^{(0,20)}$ & $58,49^{(2,37)}$ \\
\hline Prob $>$ F' & 0,0268 & 0,5706 & 0,3248 & 0,0221 \\
\hline Prob $>\mathrm{T}$ & 0,4012 & 0,7645 & 0,6552 & 0,5508 \\
\hline
\end{tabular}

${ }^{*}$ Erro padrão da média.

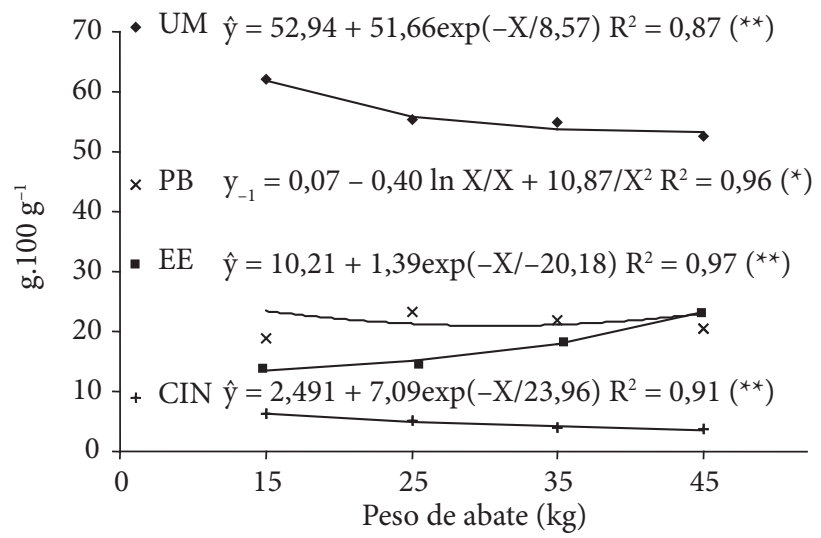

Figura 1. Equação de regressão do EE, PB, CIN e UM da costeleta dos cordeiros Santa Inês, em diferentes pesos de abate.

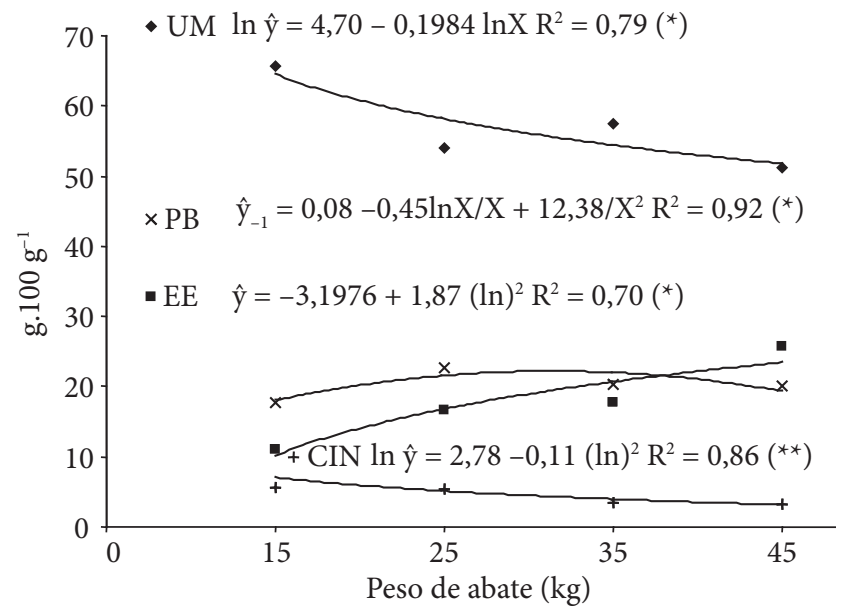

Figura 2. Equação de regressão dos componentes químicos EE, PB, CIN e UM da costeleta dos cordeiros Bergamácia, em diferentes pesos de abate. 
que a aceleração da taxa de deposição deste componente ocorre a partir dos $35 \mathrm{~kg}$ de peso vivo. Para Berg e Butterfield (1976), a maturidade é refletida por um incremento na proporção de gordura, sendo acompanhada por uma diminuição na proporção de água e proteína no corpo do animal.

De acordo com a linha de regressão (Figura 2), o decréscimo da quantidade de proteína é mais nítido nos cordeiros Bergamácia do que nos Santa Inês, o que para Kemp et al. (1981) é normal, pois segundo estes autores, a gordura química aumenta linearmente com o peso da carcaça, enquanto a umidade e a proteína diminuem com o aumento do peso e idade do animal.

Os valores médios dos componentes químicos da costela/ fralda dos cordeiros Santa Inês e Bergamácia são apresentados na Tabela 2. Verificaram-se pelo teste $T$ diferenças entre raças quanto ao teor de proteína bruta, e pela probabilidade de F quanto ao teor de minerais. A raça Bergamácia apresentou, de forma geral, uma maior quantidade de cinzas $\left(4,35 \mathrm{~g} .100 \mathrm{~g}^{-1}\right)$ presentes na costela/fralda, enquanto que a raça Santa Inês apresentou maior incremento protéico à medida que houve aumento no peso vivo do animal. Considerando a associação positiva que existe entre minerais e tecido ósseo; proteína e tecido muscular, a mesma diferença foi encontrada na composição física para as raças em relação à percentagem de tecido ósseo e muscular. A raça Bergamácia apresentou uma maior quantidade de osso $\left(25,35\right.$ g. $\left.100 \mathrm{~g}^{-1}\right)$ e a Santa Inês, maior quantidade de músculo $\left(47,82\right.$ g. $\left.100 \mathrm{~g}^{-1}\right)$.

A quantidade de gordura ou extrato etéreo não apresentou diferença significativa entre raças nem na composição física nem química deste corte, no entanto, observou-se que a raça Santa Inês apesar de apresentar em 34,50 g.100 g-1 de gordura física, demonstrou através do valor encontrado $\left(26,13\right.$ g. $\left.100 \mathrm{~g}^{-1}\right)$, menor quantidade de gordura química. A raça Bergamácia, portanto, pode ser considerada mais precoce devido à deposição antecipada de gordura. Isso pode ser confirmado ao se observar o teor de umidade da costela/fralda destes animais, o qual diminui linearmente e mais rapidamente em comparação à raça Santa Inês. Campion et al. (1976) citados por Poveda (1984) observaram que a percentagem de proteína não apresentou diferenças significativas ao aumentar o peso da carcaça, assim como as percentagens de umidade e gordura estiveram inversamente correlacionadas, aumentando a gordura e diminuindo a umidade com o incremento do peso do animal.

Robelin et al. (1997) em um estudo com cordeiros sacrificados de 1 a 16 semanas, com 4,8 a 32,5 kg de peso vivo, respectivamente, observaram que a percentagem de água diminuiu e a de gordura aumentou, enquanto a de proteína foi praticamente constante. Com relação à costela/fralda isso não ocorreu, ou seja, houve uma diminuição na percentagem de proteína do corte com o incremento do peso vivo, o que pode ser observado nas Figuras 3 e 4, todavia, deve-se considerar que a análise química foi feita em um corte da carcaça e não na carcaça como um todo, sendo de conhecimento que a composição química pode ser diferente nas diferentes partes do corpo.

O ritmo de deposição de extrato etéreo aumentou a partir dos $25 \mathrm{~kg}$ de peso vivo, tanto para a raça Santa Inês quanto para a Bergamácia (Figuras 3 e 4), porém o que as diferencia é a inten- sidade de deposição desse componente químico. Inversamente ao extrato etéreo, no mesmo ponto, inicia-se uma diminuição na percentagem de água presente no corte.

Com base nos valores médios apresentados na Tabela 3, que diz respeito à composição química do lombo dos cordeiros Santa Inês e Bergamácia, observou-se apenas diferença significativa

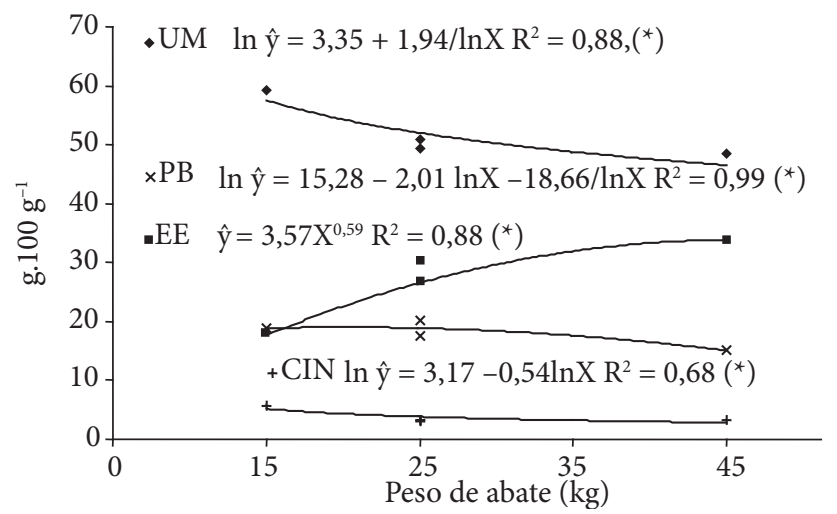

Figura 3. Equação de regressão dos componentes químicos $\mathrm{EE}, \mathrm{PB}$, CIN e UM da costela/fralda dos cordeiros Santa Inês, em diferentes pesos de abate.

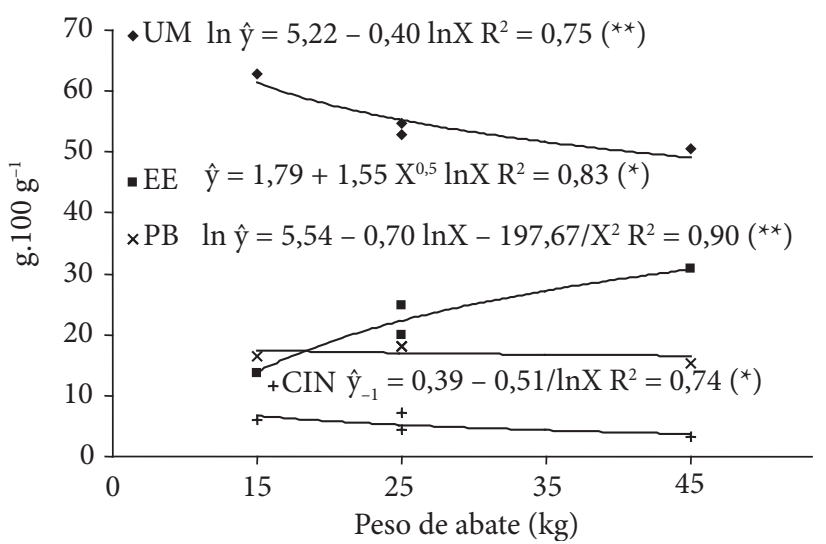

Figura 4. Equação de regressão dos componentes químicos EE, PB, CIN e UM da costela/fralda dos cordeiros Bergamácia, em diferentes pesos de abate.

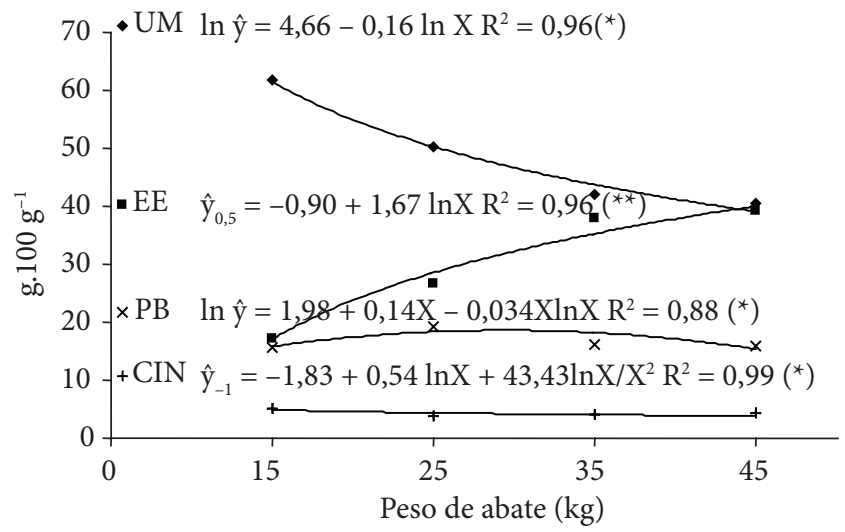

Figura 5. Equação de regressão dos componentes químicos EE, PB, CIN e UM do lombo de cordeiros Santa Inês, em diferentes pesos de abate. 
quanto ao teor de proteína bruta, na qual a raça Santa Inês superou a Bergamácia em $2 \%$ de diferença, o que é significativo em termos produtivos e de valorização do corte.

Na Figura 6 é possível notar através da linha de regressão da proteína, que o teor se manteve constante à medida que aumentou o peso dos cordeiros Santa Inês.

A perna é um corte caracterizado como nobre devido à quantidade de tecido muscular presente, sendo assim, é possível notar que o teor de proteína deste corte foi superior aos demais, tanto para a raça Santa Inês quanto para Bergamácia, desta forma os valores médios de umidade presente neste corte também são elevados, isso porque a proteína corporal é responsável pela captação da molécula de água. Kirton e Barton (1962) citados por Poveda (1984) indicaram a existência de uma maior correlação de proteína e água com o peso da carcaça, enquanto Campion et al. (1976) citados por Poveda (1984) verificaram que as percentagens de umidade estavam inversamente correlacionadas com o incremento do peso vivo, sendo o mesmo detectado por Kemp et al. (1981).

Nas Figuras 7 e 8 estão as equações e linhas de regressão referentes ao ritmo de deposições dos componentes químicos

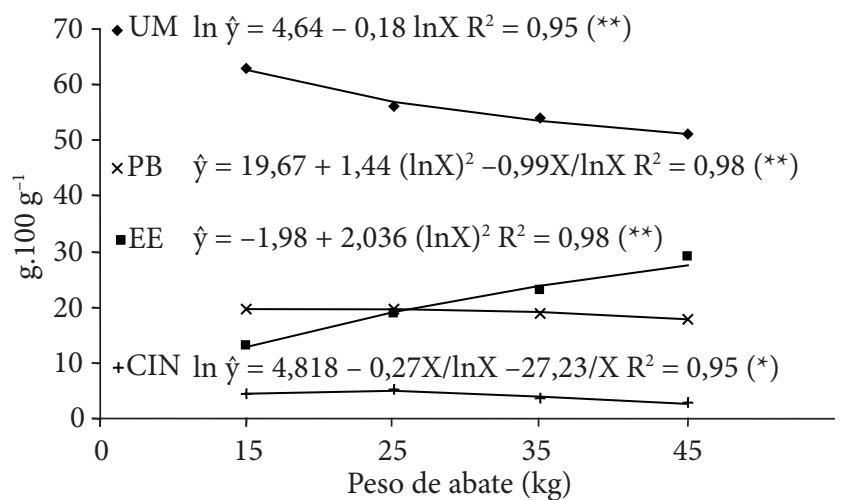

Figura 6. Equação de regressão dos componentes químicos EE, PB, CIN e UM do lombo de cordeiros Bergamácia, em diferentes pesos de abate.

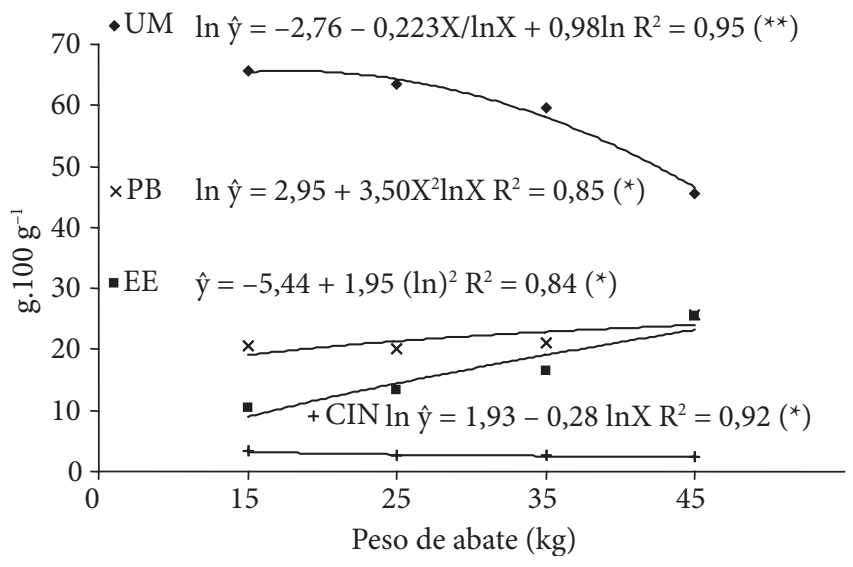

Figura 7. Equação de regressão dos componentes químicos $\mathrm{EE}, \mathrm{PB}$, CIN e UM da perna de cordeiros Santa Inês, em diferentes pesos de abate. na perna dos cordeiros Santa Inês e Bergamácia, respectivamente.

O ritmo de deposição de gordura foi mais acelerado nos cordeiros Bergamácia do que nos Santa Inês, os quais mantiveram uma intensidade de deposição de proteína constante até os $45 \mathrm{~kg}$ de peso vivo, o que só reforça a sua aptidão para produzir carne.

Analisando a variação que ocorre no teor de umidade entre as duas raças, é permitido concluir que a Bergamácia diminui drasticamente aos $45 \mathrm{~kg}$ de peso vivo, isso lhe dá uma característica de precocidade para deposição de gordura a uma idade mais jovem, prejudicando assim a qualidade do corte.

A quantidade de água pode variar de músculo para músculo dentro de espécies, mas geralmente esta variação é pequena, como, por exemplo, entre cabras e cordeiros. Em geral, os animais jovens apresentam maior teor de umidade.

As Tabelas 5, 6, 7, 8 e 9 apresentam a comparação entre cortes quanto à composição química em termos de umidade, proteína bruta, cinzas, extrato etéreo e energia, respectivamente.

Na Tabela 5, observa-se que para a raça Santa Inês, a perna é o corte que possui mais conteúdo de água em sua composição, seguida do lombo e da costeleta, o que pode ser explicado pela presença em proporção de tecido muscular nestes cortes. A costela/fralda, que já é um corte característico pela presença de gordura, apresentou menores teores de umidade em todos os pesos de abate avaliados. Os animais sacrificados aos $45 \mathrm{~kg}$, que já são de idade mais avançada, apresentaram maiores teores de umidade na perna do que na costela/fralda, o que confirma a presença de quantidade significativa de músculo.

Para a raça Bergamácia, a quantidade de água presente na composição da perna foi muito menor que na Santa Inês, já que os animais apresentaram um decréscimo de umidade aos $45 \mathrm{~kg}$ de peso vivo, no valor de 45,50 g. $100 \mathrm{~g}^{-1}$, enquanto que os da Santa Inês atingiram este peso com 54,55 g. $100 \mathrm{~g}^{-1}$ de umidade na composição da perna. Analisando os demais cortes, o decréscimo rápido no conteúdo de água aconteceu não apenas

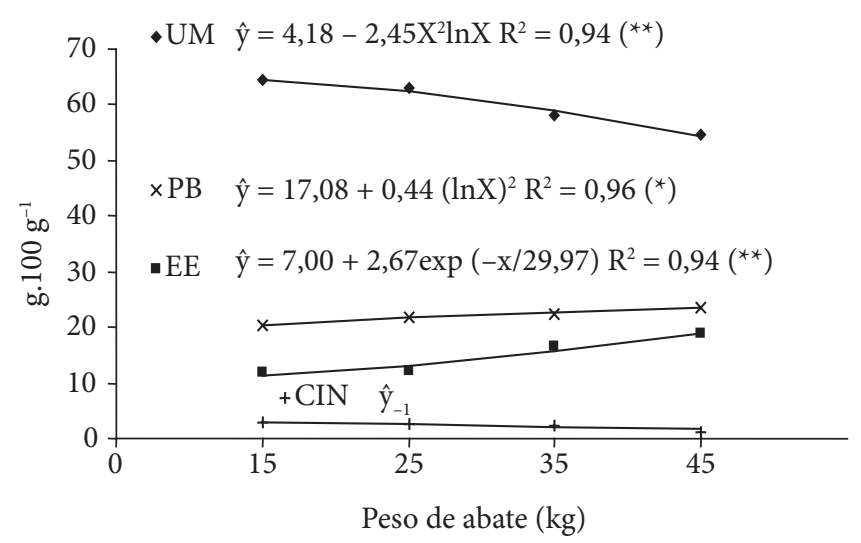

Figura 8. Equação de regressão dos componentes químicos EE, PB, CIN e UM da perna de cordeiros Bergamácia, em diferentes pesos de abate. 
Tabela 5. Comparação dos valores médios e respectivos erros padrão da umidade na matéria natural dos cortes da carcaça de cordeiros Santa Inês e Bergamácia, em diferentes pesos de abate.

\begin{tabular}{|c|c|c|c|c|}
\hline $\begin{array}{c}\text { Peso de } \\
\text { abate }\end{array}$ & Perna & Costeleta & $\begin{array}{c}\text { Costela/ } \\
\text { fralda }\end{array}$ & Lombo \\
\hline $\mathrm{kg}$ & \multicolumn{4}{|c|}{ g. $100 \mathrm{~g}^{-1}$} \\
\hline \multicolumn{5}{|l|}{ Santa Inês } \\
\hline 15 & $64,39^{(0,73) * a}$ & $61,99^{(0,92) b}$ & $59,20^{(1,45) \mathrm{b}}$ & $63,03^{(0,67) a}$ \\
\hline 25 & $63,12^{(0,78) \mathrm{a}}$ & $55,24^{(0,58) \mathrm{b}}$ & $51,01^{(0,86) c}$ & $56,12^{(0,70) b}$ \\
\hline 35 & $58,15^{(0,35) \mathrm{a}}$ & $54,94^{(0,60) \mathrm{b}}$ & $49,30^{(0,52) c}$ & $54,00^{(0,31) \mathrm{b}}$ \\
\hline 45 & $54,55^{(1,77) a}$ & $52,52^{(0,41) \mathrm{b}}$ & $48,52^{(0,96) c}$ & $51,03^{(0,50) \mathrm{b}}$ \\
\hline \multicolumn{5}{|l|}{ Bergamácia } \\
\hline 15 & $65,55^{(0,72) \mathrm{a}}$ & $65,62^{(1,34) a}$ & $61,83^{(0,45) b}$ & $62,87^{(0,35) b}$ \\
\hline 25 & $63,40^{(0,84) a}$ & $54,10^{(1,07) \mathrm{b}}$ & $50,18^{(0,05) c}$ & $54,62^{(1,27) b}$ \\
\hline 35 & $59,40^{(0,43) \mathrm{a}}$ & $57,37^{(0,30) \mathrm{a}}$ & $41,95^{(0,43) \mathrm{b}}$ & $52,85^{(0,84) \mathrm{b}}$ \\
\hline 45 & $45,50^{(0,91) \mathrm{a}}$ & $51,23^{(0,79) \mathrm{a}}$ & $40,51^{(0,69) \mathrm{b}}$ & $50,56^{(0,87) \mathrm{a}}$ \\
\hline \multicolumn{5}{|l|}{ Média geral } \\
\hline 15 & $64,78^{(0,55)}$ & $63,20^{(0,93)}$ & $60,08^{(1,04)}$ & $62,97^{(0,44)}$ \\
\hline 25 & $63,21^{(0,56)}$ & $54,93^{(1,38)}$ & $50,73^{(0,57)}$ & $55,62^{(0,63)}$ \\
\hline 35 & $58,60^{(0,34)}$ & $55,75^{(1,70)}$ & $46,85^{(1,27)}$ & $53,62^{(0,37)}$ \\
\hline 45 & $51,53^{(1,91)}$ & $52,09^{(1,23)}$ & $45,85^{(1,48)}$ & $50,80^{(0,41)}$ \\
\hline Prob > F' & 0,0001 & 0,0001 & 0,0001 & 0,0001 \\
\hline
\end{tabular}

Médias seguidas da mesma letra na linha não são diferentes entre si pelo Teste de Tukey $(\mathrm{p}<0,05) .{ }^{\star}$ Erro padrão da média.

Tabela 6. Comparação dos valores médios e respectivos erros padrão de proteína bruta na matéria natural dos cortes da carcaça de cordeiros Santa Inês e Bergamácia abatidos com diferentes pesos.

\begin{tabular}{ccccc}
\hline $\begin{array}{c}\text { Peso de } \\
\text { abate }\end{array}$ & Perna & Costeleta & $\begin{array}{c}\text { Costela/ } \\
\text { fralda }\end{array}$ & Lombo \\
\cline { 2 - 5 } kg & & \multicolumn{3}{c}{ g.100 g ${ }^{-1}$} \\
\hline Santa Inês & & & \\
\hline 15 & $20,27^{(0,16)^{*} \mathrm{a}}$ & $18,83^{(0,68) \mathrm{a}}$ & $18,86^{(0,53) \mathrm{a}}$ & $19,63^{(0,73) \mathrm{a}}$ \\
25 & $21,84^{(0,76) \mathrm{ab}}$ & $23,24^{(0,58) \mathrm{a}}$ & $20,17^{(0,57) \mathrm{b}}$ & $19,77^{(0,69) \mathrm{b}}$ \\
35 & $22,50^{(0,39) \mathrm{a}}$ & $21,90^{(0,22) \mathrm{a}}$ & $17,57^{(0,21) \mathrm{b}}$ & $19,00^{(0,50) \mathrm{b}}$ \\
45 & $23,54^{(1,40) \mathrm{a}}$ & $20,49^{(0,55) \mathrm{b}}$ & $15,11^{(0,41) \mathrm{c}}$ & $17,93^{(0,40) \mathrm{c}}$ \\
\hline Bergamácia & & & & \\
\hline 15 & $20,41^{(0,43) \mathrm{a}}$ & $17,71^{(0,71) \mathrm{b}}$ & $15,57^{(0,76) \mathrm{c}}$ & $16,55^{(0,50) \mathrm{c}}$ \\
25 & $20,00^{(1,24) \mathrm{a}}$ & $22,77^{(1,24) \mathrm{a}}$ & $19,26^{(0,46) \mathrm{b}}$ & $18,05^{(1,28) \mathrm{b}}$ \\
35 & $21,07^{(0,24) \mathrm{a}}$ & $20,37^{(0,53) \mathrm{a}}$ & $16,11^{(0,72) \mathrm{c}}$ & $18,02^{(0,17) \mathrm{b}}$ \\
45 & $25,62^{(0,45) \mathrm{a}}$ & $20,06^{(0,62) \mathrm{b}}$ & $15,84^{(1,06) \mathrm{c}}$ & $15,39^{(1,10) \mathrm{c}}$ \\
\hline Média geral & & & & \\
\hline 15 & $20,31^{(0,46)}$ & $18,46^{(0,52)}$ & $17,77^{(0,33)}$ & $18,60^{(0,71)}$ \\
25 & $21,22^{(0,68)}$ & $23,08^{(0,52)}$ & $19,87^{(0,42)}$ & $19,20^{(0,64)}$ \\
35 & $22,02^{(0,35)}$ & $21,39^{(0,33)}$ & $17,08^{(0,34)}$ & $18,67^{(0,36)}$ \\
45 & $24,23^{(0,97)}$ & $20,35^{(0,40)}$ & $15,36^{(0,42)}$ & $17,08^{(0,59)}$ \\
\hline Prob > F' & 0,0011 & 0,0001 & 0,0001 & 0,2085
\end{tabular}

Médias seguidas da mesma letra na linha não são diferentes entre si pelo Teste de Tukey $(0,05)$. *Erro padrão da média.

com a perna, e sim com a costeleta, costela/fralda e lombo, o que caracteriza que a raça Bergamácia apresenta maior propensão para deposição de gordura a partir dos $35 \mathrm{~kg}$ de peso vivo.

Observando-se os valores de proteína bruta na Tabela 6, confirmam-se os dados encontrados na Tabela 5 quanto aos valores de umidade. A perna foi o corte que apresentou maior teor de proteína em g. $100 \mathrm{~g}^{-1}$, sendo que o teor de umidade
Tabela 7. Comparação dos valores médios e respectivos erros padrão de cinzas na matéria natural dos cortes da carcaça de cordeiros Santa Inês e Bergamácia abatidos com diferentes pesos.

\begin{tabular}{|c|c|c|c|c|}
\hline $\begin{array}{c}\text { Peso de } \\
\text { abate }\end{array}$ & Perna & Costeleta & $\begin{array}{c}\text { Costela/ } \\
\text { fralda }\end{array}$ & Lombo \\
\hline $\mathrm{kg}$ & \multicolumn{4}{|c|}{ g. $100 \mathrm{~g}^{-1}$} \\
\hline \multicolumn{5}{|l|}{ Santa Inês } \\
\hline 15 & $2,97^{(0,28)^{*} \mathrm{c}}$ & $6,24^{(0,44) a}$ & $5,67^{(0,85) \mathrm{a}}$ & $4,46^{(0,79) \mathrm{b}}$ \\
\hline 25 & $2,57^{(0,27) \mathrm{b}}$ & $5,19^{(0,51) \mathrm{a}}$ & $2,98^{(0,50) b}$ & $5,15^{(5,15) \mathrm{a}}$ \\
\hline 35 & $2,22^{(0,40) b}$ & $3,88^{(0,63) \mathrm{a}}$ & $3,29^{(0,49) \mathrm{a}}$ & $3,79^{(3,79) \mathrm{a}}$ \\
\hline 45 & $2,26^{(0,53) \mathrm{b}}$ & $3,69^{(0,37) \mathrm{a}}$ & $3,38^{(0,68) a}$ & $2,84^{(2,84) \mathrm{b}}$ \\
\hline \multicolumn{5}{|l|}{ Bergamácia } \\
\hline 15 & $3,27^{(0,56) \mathrm{b}}$ & $5,71^{(0,17) \mathrm{a}}$ & $5,04^{(0,77) a}$ & $6,14^{(0,10) a}$ \\
\hline 25 & $2,63^{(0,36) c}$ & $5,43^{(0,88) a}$ & $3,87^{(0,48) c}$ & $7,10^{(1,16) a}$ \\
\hline 35 & $2,26^{(0,40) c}$ & $3,48^{(0,29) b}$ & $4,07^{(0,64) \mathrm{a}}$ & $4,37^{(0,30) \mathrm{a}}$ \\
\hline 45 & $2,37^{(0,12) c}$ & $3,30^{(0,47) \mathrm{b}}$ & $4,42^{(0,69) \mathrm{a}}$ & $3,19^{(0,58) \mathrm{b}}$ \\
\hline \multicolumn{5}{|l|}{ Média geral } \\
\hline 15 & $3,07^{(0,25)}$ & $6,07^{(0,30)}$ & $5,46^{(0,60)}$ & $5,02^{(0,58)}$ \\
\hline 25 & $2,59^{(0,20)}$ & $5,27^{(0,42)}$ & $3,28^{(0,38)}$ & $5,80^{(0,57)}$ \\
\hline 35 & $2,23^{(0,28)}$ & $3,75^{(0,42)}$ & $3,55^{(0,39)}$ & $3,98^{(0,24)}$ \\
\hline 45 & $2,29^{(0,34)}$ & $3,56^{(0,28)}$ & $3,72^{(0,51)}$ & $2,96^{(0,25)}$ \\
\hline Prob $>F^{\prime}$ & 0,8261 & 0,2296 & 0,0772 & 0,0065 \\
\hline
\end{tabular}

Médias seguidas da mesma letra na linha não são diferentes entre si pelo Teste de Tukey $(0,05)$. ${ }^{*}$ Erro padrão da média.

Tabela 8. Comparação dos valores médios e respectivos erros padrão de extrato etéreo na matéria natural dos cortes da carcaça de cordeiros Santa Inês e Bergamácia abatidos com diferentes pesos.

\begin{tabular}{|c|c|c|c|c|}
\hline $\begin{array}{c}\text { Peso de } \\
\text { abate }\end{array}$ & Perna & Costeleta & $\begin{array}{c}\text { Costela/ } \\
\text { fralda }\end{array}$ & Lombo \\
\hline $\mathrm{kg}$ & & & g. $100 \mathrm{~g}^{-1}$ & \\
\hline \multicolumn{5}{|l|}{ Santa Inês } \\
\hline 15 & $11,85^{(0,52)^{\star} \mathrm{b}}$ & $12,92^{(0,39) b}$ & $16,26^{(0,43) \mathrm{a}}$ & $13,19^{(0,69) \mathrm{b}}$ \\
\hline 25 & $12,12^{(0,82) c}$ & $15,55^{(0,30) c}$ & $25,66^{(0,76) \mathrm{a}}$ & $18,94^{(0,58) \mathrm{b}}$ \\
\hline 35 & $16,45^{(0,44) c}$ & $17,76^{(0,19) c}$ & $29,65^{(0,87) \mathrm{a}}$ & $23,19^{(0,65) \mathrm{b}}$ \\
\hline 45 & $18,80^{(1,10) c}$ & $23,29^{(0,70) \mathrm{b}}$ & $32,98^{(0,39) \mathrm{a}}$ & $28,01^{(0,62) a b}$ \\
\hline \multicolumn{5}{|l|}{ Bergamácia } \\
\hline 15 & $10,44^{(0,71) \mathrm{b}}$ & $10,95^{(0,82) \mathrm{b}}$ & $17,21^{(0,35) \mathrm{a}}$ & $13,76^{(0,75) b}$ \\
\hline 25 & $13,28^{(0,44) \mathrm{d}}$ & $16,69^{(0,82) \mathrm{cd}}$ & $26,67^{(0,52) \mathrm{a}}$ & $19,88^{(0,47) \mathrm{b}}$ \\
\hline 35 & $16,49^{(1,03) c}$ & $17,77^{(0,91) c}$ & $37,86^{(0,67) \mathrm{a}}$ & $24,75^{(0,84) \mathrm{b}}$ \\
\hline 45 & $25,50^{(0,48) c}$ & $25,73^{(0,45) c}$ & $39,23^{(0,43) \mathrm{a}}$ & $30,85^{(1,42) \mathrm{b}}$ \\
\hline \multicolumn{5}{|l|}{ Média geral } \\
\hline 15 & $11,38^{(0,46)}$ & $12,26^{(0,47)}$ & $16,57^{(0,33)}$ & $13,38^{(0,50)}$ \\
\hline 25 & $12,51^{(0,58)}$ & $15,93^{(0,36)}$ & $25,99^{(0,54)}$ & $19,26^{(0,43)}$ \\
\hline 35 & $16,46^{(0,41)}$ & $17,76^{(0,29)}$ & $32,06^{(1,49)}$ & $23,71^{(0,55)}$ \\
\hline 45 & $21,03^{(1,33)}$ & $24,10^{(0,62)}$ & $35,06^{(1,07)}$ & $28,95^{(0,74)}$ \\
\hline Prob > F' & 0,0001 & 0,0001 & 0,0001 & 0,0001 \\
\hline
\end{tabular}

Médias seguidas da mesma letra na linha não são diferentes entre si pelo Teste de Tukey $(0,05)$. ${ }^{*}$ Erro padrão da média.

está altamente correlacionado aos teores de proteína e não de gordura.

Depois da perna, nos cordeiros Santa Inês e Bergamácia, os cortes que apresentaram maior teor de proteína foram a costeleta e o lombo, ambos com pouca variação nos pesos de abate.

A comparação entre cortes dos valores médios em g. $100 \mathrm{~g}^{-1}$ de cinzas é mostrada na Tabela 7. A costeleta dos cordeiros San- 
Tabela 9. Comparação dos valores médios e respectivos erros padrão de energia dos cortes da carcaça de cordeiros Santa Inês e Bergamácia abatidos com diferentes pesos.

\begin{tabular}{|c|c|c|c|c|}
\hline $\begin{array}{c}\text { Peso de } \\
\text { abate }\end{array}$ & Perna & Costeleta & $\begin{array}{c}\text { Costela/ } \\
\text { fralda }\end{array}$ & Lombo \\
\hline $\mathrm{kg}$ & \multicolumn{4}{|c|}{ Kcal.kg-1 } \\
\hline \multicolumn{5}{|c|}{ Santa Inês } \\
\hline 15 & $4035,67^{(337,64)^{*} \mathrm{a}}$ & $4460,38^{(363,27) a}$ & $4332,88^{(264,90) a}$ & $4289,45^{(327,27) a}$ \\
\hline 25 & $4324,20^{(110,26) \mathrm{b}}$ & $4528,13^{(253,77) \mathrm{b}}$ & $4805,87^{(189,35) a}$ & $4375,03^{(233,04) b}$ \\
\hline 35 & $4528,22^{(157,55) b}$ & $4550,73^{(351.81) \mathrm{b}}$ & $5280,43^{(305,41) a}$ & $4785,70^{(128,52) b}$ \\
\hline 45 & $4484,17^{(289,72) c}$ & $5019,77^{(411,42) \mathrm{b}}$ & $5312,20^{(284,28) a}$ & $4980,03^{(401,07) \mathrm{b}}$ \\
\hline \multicolumn{5}{|c|}{ Bergamácia } \\
\hline 15 & $3992,13^{(309,15) b}$ & $3884,77^{(52,29) \mathrm{b}}$ & $4480,77^{(62,17) \mathrm{a}}$ & $4203,00^{(457,77) a b}$ \\
\hline 25 & $4539,70^{(233,17) a}$ & $4354,70^{(73,66) \mathrm{b}}$ & $4767,63^{(96,80) a}$ & $4372,83^{(557,56) \mathrm{b}}$ \\
\hline 35 & $4691,57^{(17,91) \mathrm{b}}$ & $4491,00^{(508,41) \mathrm{b}}$ & $5327,13^{(214,58) a}$ & $4409,60^{(14,02) \mathrm{b}}$ \\
\hline 45 & $4959,80^{(51,65) \mathrm{b}}$ & $5221,47^{(331,88) b}$ & $5797,90^{(55,35) \mathrm{a}}$ & $5094,63^{(572,14) \mathrm{b}}$ \\
\hline \multicolumn{5}{|l|}{ Raça } \\
\hline SI & $4343,06^{(119,94)}$ & $4639,75^{(169.52)}$ & $4932,84^{(148,96)}$ & $4607,55^{(148,16)}$ \\
\hline BG & $4545,80^{(135,26)}$ & $4487,98^{(195,00)}$ & $5093,33^{(192,59)}$ & $4520,01^{(221,59)}$ \\
\hline Prob > F' & 0,4393 & 0,4825 & 0,7830 & 0,7830 \\
\hline Prob $>\mathrm{T}$ & 0,2720 & 0,5619 & 0,5161 & 0,7459 \\
\hline
\end{tabular}

Médias seguidas da mesma letra na linha não são diferentes entre si pelo Teste de Tukey $(0,05)$.

ta Inês foi o corte que apresentou maior quantidade de cinzas na composição, seguida do lombo e da costela/fralda, já nos Bergamácia, o lombo superou os demais cortes, apresentando um valor de 7,10 g.100 g $\mathrm{g}^{-1}$ de matéria mineral para os animais sacrificados aos $25 \mathrm{~kg}$ de peso vivo.

É possível observar que em todos os cortes ocorreu um pequeno decréscimo, em proporção, no teor de cinzas. Conrad et al. (1985) afirmam que a proporção com que os minerais são depositados no corpo depende da composição do ganho, onde qualquer alteração nesta modificará a composição mineral e, conseqüentemente, os requerimentos líquidos para ganho. Todavia, o ARC (1980) cita que a concentração de cinzas tem seu conteúdo aumentado à medida que o peso vivo do animal aumenta, sendo o último componente a diminuir sua deposição corporal.

De acordo com os resultados apresentados na Tabela 7, não é percebido este aumento que o $\mathrm{ARC}^{1}$ diz ocorrer com os minerais, provavelmente esse decréscimo e até mesmo a inconstância nos valores obtidos neste trabalho, estejam relacionados à forma como a amostra do corte foi processada, ou seja, os componentes teciduais (osso, músculo e gordura) foram moídos juntos, e dificilmente conseguiu-se uma redução mínima do osso na amostra total, o que pode ter interferido na determinação tanto de proteína quanto do material mineral. Considerando-se que em torno de $3 \mathrm{~g}$ da amostra foram retirados parcialmente desengordurados para que procedesse a análise, o que pode não ter sido representativo diante da presença de partículas maiores de tecido ósseo.

No entanto, Berg et al. (1979) verificaram também que a concentração de proteína e minerais no peso ganho, de maneira geral, decresce progressivamente com a elevação do peso do animal, ocorrendo aumentos concomitantes na proporção de gordura depositada. Para Lanna et al. (1992), essas mudanças se traduzem no decréscimo de requerimentos líquidos de proteína e macro-elementos minerais para ganho, e ainda justifica estas modificações através de reduções na taxa de desenvolvimento muscular com o aumento do peso corporal vazio.

Georgievski et al. (1982) afirmam que a concentração de cinzas é pouco variável em relação à de gordura e proteína. Este tipo de comportamento pode ser observado nos gráficos ilustrados nas Figuras 1, 2, 3, 4, 5, 6, 7 e 8, onde são apresentadas as linhas de regressão referentes ao conteúdo de cinzas, ou seja, graficamente os valores preditos para este componente esclarecem a pouca variação que ocorre à medida que aumentam os pesos vivos, diferentes dos de gordura e água, que são muito variáveis.

Os conteúdos de extrato etéreo e energia, apresentados nas Tabelas 8 e 9, respectivamente, estão altamente correlacionados, ou seja, com a proximidade da maturidade do ovino em crescimento, à medida que o peso vivo se eleva, há um aumento na proporção de gordura, acompanhado de um incremento energético, que é segundo ARC (1980) e NRC (1985), devido também à desaceleração do crescimento muscular.

Quando comparados aos demais cortes, a costela/fralda seguida do lombo foram os cortes que apresentaram maiores teores de extrato etéreo em todos os pesos de abate e nas duas raças. $\mathrm{O}$ mesmo ocorreu em relação ao conteúdo energético (Tabela 9).

\section{Conclusões}

O melhor momento para o abate de cordeiros Santa Inês e Bergamácia, atendendo as características dos cortes, como menores teores de gordura, se encontra na faixa de 25 e $35 \mathrm{~kg}$ de peso vivo, em que os cortes, principalmente os considerados nobres ou de primeira categoria, como a perna, costeleta, lombo e costela/fralda, apresentariam as melhores proporções de água, proteína, gordura e minerais, refletindo melhores aspectos de qualidade para o consumidor final, e em função disso uma melhor valorização do produto oferecido ao mercado que faz tais exigências.

\section{Agradecimentos}

À Universidade Federal de Lavras - MG e especialmente ao Prof. DSc Juan Ramon Olalquiaga Pérez.

\section{Referências bibliográficas}

AGRICULTURAL RESEARCH COUNCIL (Farnham Royal, Inglaterra). The nutrient requirements of farm livestock. 3. ed. Wallingford : CAB International, 1988. $351 \mathrm{p}$.

A.O.A.C. Association of Official Analytical Chemists. Official Methods of Analysis of the Association of Official Analytical Chemists. 16. ed., Maryland, USA, 1990. 1298 p.

BERG, R. T.; BUTTERFIELD, R. M. New concepts of cattle growth. Sidney: Sidney University Press, 1976. 240 p.

BERG, R. T. et al. Patterms of carcass fat deposition in heifers, steers and bulls. Canadian Journal of Animal Science, Ottawa, v. 59, n. 2, p. 359-366, Junho 1979. 
CONRAD, J. H. et al. Minerais para ruminantes em pastejo em regiões tropicais. Campo Grande, MS: EMBRAPA-CNPG, 1985. $90 \mathrm{p}$.

GEORGIEVSKI,V. I.; ANNENKOV, B. N.; SAMOKHIN V. I. Mineral nutrition of animals. Studies in the agricultural and food science. Wellington: Butterworths, 1982. 475 p.

HAMMOND, J. Growth and development of mutton qualities in the sheep. Edinburgh: Oliver and Boyd, 1932.

KEMP, J. D. et al. Effect of feeding systems, slaughter weight and sex on organoleptic properties, and fatty acid composition of lamb. Journal Animal Science, Cambridge, v. 51, n. 2, p. 321-330, agosto 1981.

LANNA, R. P. et al. Composição corporal e do ganho de peso e exigências de energia, proteína e macroelementos minerais $(\mathrm{Ca}$, $\mathrm{P}, \mathrm{Mg}, \mathrm{Na}$ e K), de novilhos de cinco grupos raciais. 1. Conteúdo corporal e do ganho de peso em gordura, proteína e energia. Revista da Sociedade Brasileira de Zootecnia, Viçosa, v. 21, n. 3, p. 518-527, maio/jun. 1992.

LANNA, D. P. D. Estimativa da composição química do corpo vazio de taurinhos nelore através da gravidade especifica da carcaça e da composição de cortes das costelas. 1998, 131 p. Dissertação (Mestrado em Agronomia) - Escola Superior de Agricultura Luiz de Queiroz, Piracicaba - SP.
NATIONAL RESEARCH COUNCIL (NRC). Nutrient requeriments of domestic animals: Nutrient requeriments of sheep. Washington, Wallingford: CABI Publishing, 1985, 99 p.

PALSSON, H. Avances em fisiologia zootécnica. Zaragoza: Acribia, Cap.10: Conformacíon y composición del cuerpo. p. 510-641. 1959.

POVEDA, M. C. Crescimiento y características de la canal de corderos merinos. Influencia del peso de sacrificio, del sexo y de la incorporación de pulpa de acetuna a la dieta. 1984, 225 p. Tesis (Doctoral). Instituto Nacional de Investigations Agrarias INIA. Madrid.

ROBELIN, J. et al. Evolution de la composition chimique des jeunes ageneause mâles jusquí a âge de 16 semaines. Animal Zootech, Amsterdam, v. 26, n. 3, p. 68-81, 1977.

SANTOS, C. L. Estudo do desenvolvimento, das características da carcaça e do cresimento alométrico de cordeiros das raças Santa Inês e Bergamácia., 1999. 143 p. Dissertação (Mestrado em Zootecnia) - Universidade Federal de Lavras, Lavras.

SANTOS, C. L.; PEREZ, J. O. P. Cortes comerciais de cordeiros Santa Inês. In: I ENCONTRO MINEIRO DE OVINOCULTURA. Lavras. Anais..., Lavras: UFLA, 2000. p.150-168.

SAS INSTITUTE Inc. SAS/ETS ${ }^{\circledR}$ User's guide. Version 6. 2. ed. Carolina:Cray:SAS Institute Inc., 1996. 